\title{
IMPACT OF VEHICLES ON URBAN AIR QUALITY: PREDICTIVE ASSESSMENT WITH AN APPLICATION TO TIRUMALA
}

\author{
Rama Kanth Angatha ${ }^{1}$, Arpan Mehar ${ }^{2}$ \\ 1,2 Transportation Division, Department of Civil Engineering, National Institute of Technology, Waragnal, \\ Telangana, India
}

Received 5 June 2019; accepted 3 October 2019

\begin{abstract}
On road vehicular traffic is the major responsible source for overall air pollution in an urban city. The emission of various pollutants and smog from tail pipe of vehicles are decaying the quality of air in urban cities. The present study accentuates the contribution of vehicles growth on air pollution observed in Tirumala town over the span of three years. The relative percentage increase of traffic volume and each pollutant category from the year 2015 to 2025 has been estimated. The relationship between the Annual Average Daily Traffic (AADT) and Annual Average Pollutant Concentration (AAPC) has been studied to examine the impact of vehicles growth on air pollution. The correlation analysis has been done between traffic volume and air pollutant concentrations to examine the impact of vehicles growth on air pollution. The time series analysis has been done for prediction of air pollution and traffic volume growth for the years 2020 and 2025. Based on the results obtained in the study, it is clearly evident that vehicles are the primary contributors for the total air pollution in Tirumala. This study also indicated that the air pollution level in Tirumala town in 2025 would be much more hazardous. The study also tried to provide some recommendations to reduce the pollution level in the coming years in Tirumala town. In this context, there is an immense need for the Pollution Control Board authorities to implement certain mitigation measures to improve the air quality in Tirumala town.
\end{abstract}

Keywords: traffic volume, air pollution, prediction, relationship.

\section{Introduction}

The road transport has become a common and necessary component of everyday life. Transportation is the largest source of air pollution in major cities, it is estimated at around $70 \%$ of urban air pollution caused by vehicular activities (Wilson and Henshaw, 2016). Despite its value, flexibility and necessary as parts of modern society, the road transport is recognized as having a major contribution to undesirable environmental problems. The transport sector, especially road traffic, constitutes a major source of pollutant emissions. The primary air pollutants emitted by motor vehicles are carbon monoxide (CO), nitrogen oxides $\left(\mathrm{NO}_{\mathrm{X}}\right.$, including $\mathrm{NO}$ and $\left.\mathrm{NO}_{2}\right)$, hydrocarbons (HCs) and particulate matters (PM). Vehicular exhaust has become a main source of air pollution. Among these emissions, $\mathrm{CO}$ and $\mathrm{NO}_{\mathrm{X}}$ emissions are accounting for more than $80 \%$ and $40 \%$ of the total urban emissions in many big cities around the world (Wang et al., 2008; Xue et al., 2010; Yang et al., 2004). Motor vehicles influence the temporal and spatial patterns of regulated gases, particulate matter

${ }^{1}$ Corresponding author: ramakanth@student.nitw.ac.in 
(PM), and air toxic pollutant concentrations. The concentration of various pollutants such as Carbon Monoxide (CO), Nitrogen dioxide $\left(\mathrm{NO}_{2}\right)$, benzene, etc., is very high at the locations adjacent to the roadways rather than the locations far away from the roadways. This is because of the release of exhaust gasses from automobiles near to the roadways (Harrison et al., 2003; Pirjola et al., 2006; Reponen et al., 2003).

The air pollution data are normally evaluated with the help of time series analysis. Time series analysis is mainly used determine the trend for future estimation of dependent variable (Alier and Tauler, 2013). In the air pollution, the future scenarios are always important to tackle with this global scale problem (Boubel et al., 2013). Characterizing the relationships between traffic volume and air pollution would aid the interpretation of previous studies and contribute to the performance of new studies. Here, the study examine the relationship between traffic volume and air pollution concentrations in Tirumala town, India which was used to estimate the relative percentage increase in traffic volume and each pollutant concentration over the years.

Study of air quality problems at the microlevel urban environment requires application of an adequate methodology that permits the understanding of the source receptor relation and to develop a proper strategy for reducing atmospheric pollution (Khare and Sharma, 1999). The evaluation of emissions with respect to spatial and temporal variations of traffic flow is required for effective analysis of the air quality.

\section{Literature Review}

Gouveia and Fletcher (2000) used various models like Poisson regression and autocorrelation for customizing the relationship between mortality and air pollution. Dominici (2004) applied semi parametric methods for time series analysis for air pollutants and mortality. Some sensitivity of generalized additive models is applied to time series data. (Davies et al., 2009) investigated on correlation between two week average road concentrations of $\mathrm{NO}_{2}$ and $\mathrm{NO}_{x}$ and short term average noise levels for 103 urban sites with traffic levels variation, environment and infrastructure characteristics. Zhou et al. (2014) worked on frequency analysis (Fourier series) with an aim to perceive the underlying physical processes and influence of emission sources on variability of air pollutant concentrations. Nagpure and Gurjar (2012) established a Vehicular air pollution inventory (VAPI) model to replace the gap between available models and tools needed in developing countries. Tchepel and Borrego (2009) examined the air pollution released from vehicles both inside and outside of tunnel in Shenghai. Different highest hourly average concentrations of various pollutants like $\mathrm{CO}, \mathrm{NO}, \mathrm{NO}_{2}, \mathrm{NO}_{\mathrm{x}}$ were identified. Nagpure et al., (2015) compared exhaust emissions of gaseous, particulate matter and mobile source air toxics together with volatile organic compounds and PM 10 from non-exhaust vehicular sources during the past and future scenarios. Catalano et al., (2016) used artificial neural network approach and ARIMAX model for air quality forecasting and explained the relationship between transports related air pollutant concentrations and easily accessible explanatory variables. Bhardwaj and Pruthi (2016) used time series analysis and predictability analysis of air pollutants in Delhi with estimation of regression coefficient, Hurst exponent, fractal dimension and predictability index. Kwak 
et al., (2018) worked on mobile monitoring and computational fluid dynamics modelling to study the spatio-temporal variations of air pollutant concentrations at high resolution in urban areas. The correlation analysis demonstrated the high emitting vehicles are deterministically answerable for poor air quality in street of canyon.

With the background of the above literature, this study aimed to analyze the impact of vehicle volume on air pollutant concentrations on urban road. This study also attempts to study the temporal variations of traffic volume along with air pollution in an urban city to predict the status of air quality for future years. To achieve these objectives, Tirumala was chosen as the study area for data collection and the details of the study area and data collection are presented in Section 3.

\section{Study Area and Data Collection}

Tirumala is a hilly terrain mountainous town which is located at $980 \mathrm{~m}$ above the mean sea level. It is located in Chittoor district, Andhra Pradesh. It is one of the religious, historical and a sacred place visited by thousands of pilgrims every day. As per the current scenario, around 8000-9000 vehicles/day are travelling to Tirumala from Tirupathi (Vigilance \& Security Department, Tirupathi, 2018). The concentration of various pollutants like $\mathrm{CO}$, $\mathrm{O}_{3}, \mathrm{NO}, \mathrm{NO}_{2}, \mathrm{NOx}, \mathrm{SO}_{2}$, Particulate Matter (PM2.5, PM 10) are recorded on hourly basis from Continuous Air Quality Monitoring Station (CAQMS). The picture of CAQMS set up is shown in Figure 2. This location is away from the vicinity of industries and other land use. Therefore, the major source of the air pollution is the traffic. The data from CAQMS were collected by Pollution Control Board (PCB), Tirupathi. The data between years 2015 to 2017 were analyzed. The traffic volume data has been recorded by the Vigilance \& Security Department of Tirupathi on the road located near to the CAQMS. The road where the traffic volume has been recorded is also shown in Figure 1 . The traffic volume data was also collected for the years 2015 to 2017 and presented in Figure 7. The pollutant concentrations of different pollutants recorded in CAQMS, Tirumala are presented in figures 3 to 7 from the years 2015-2017.

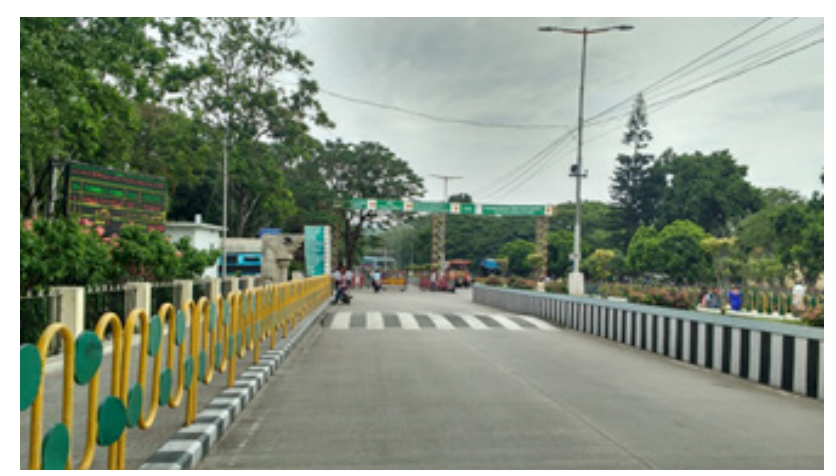

Fig. 1.

Location of The Road Where Caqms is Present and Traffic Volume is Recorded 


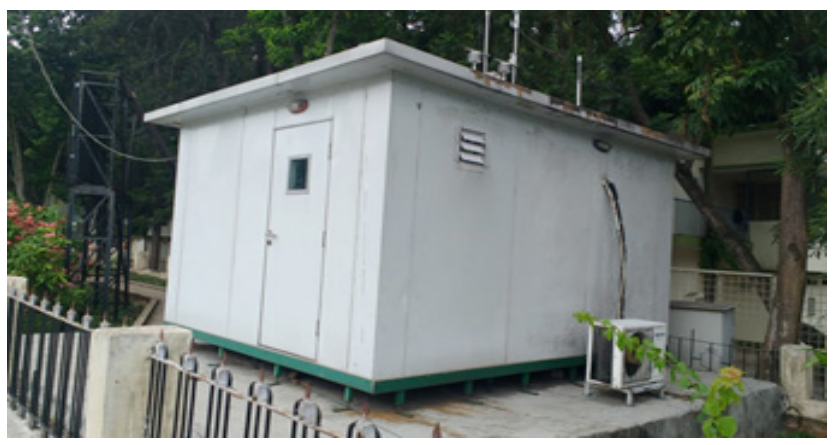

Fig. 2.

CAQMS Setup at Tirumala where the Air Pollutant Concentrations are Recorded

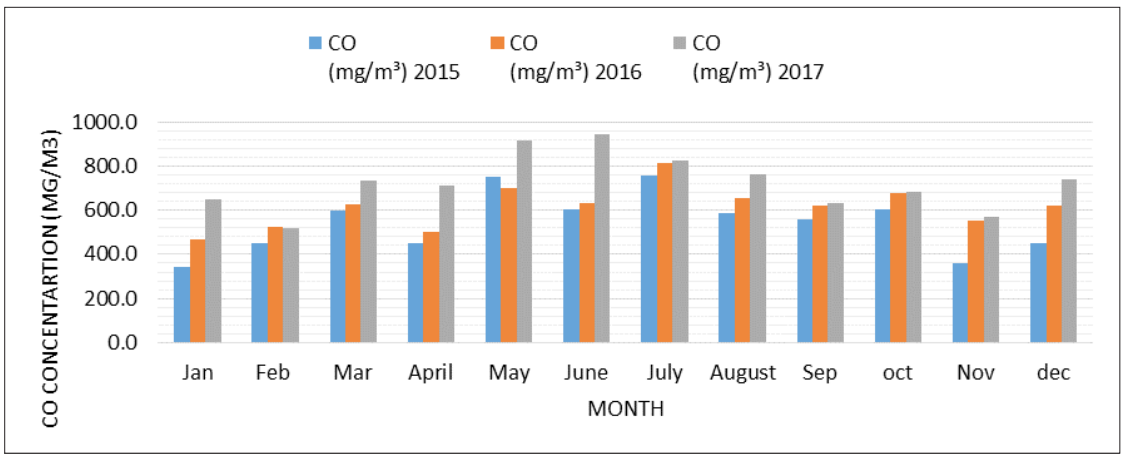

Fig. 3.

Carbon Monoxide (CO) Concentrations between 2015 and 2017

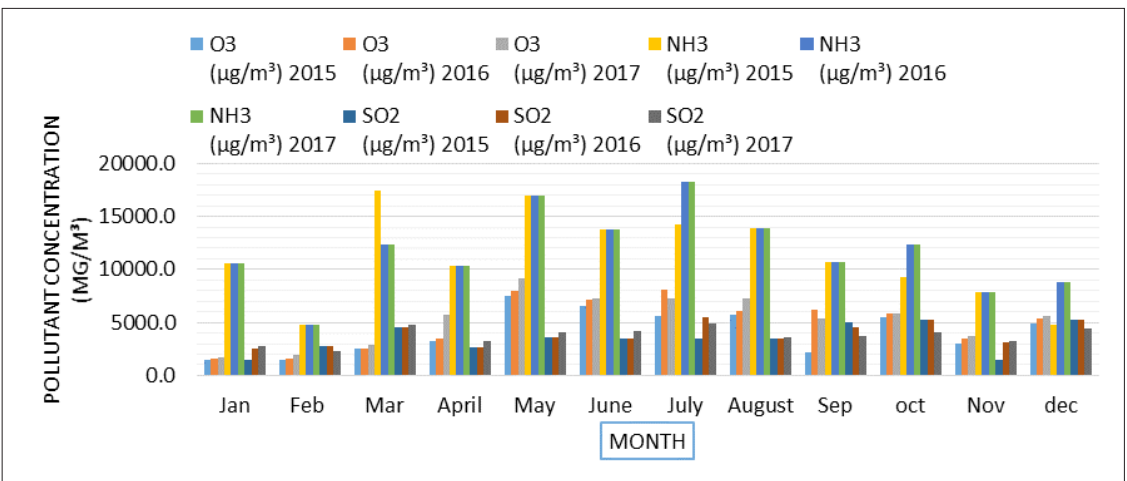

Fig. 4.

Ozone, Sulphur Dioxide and Ammonia Concentrations between 2015 and 2017 


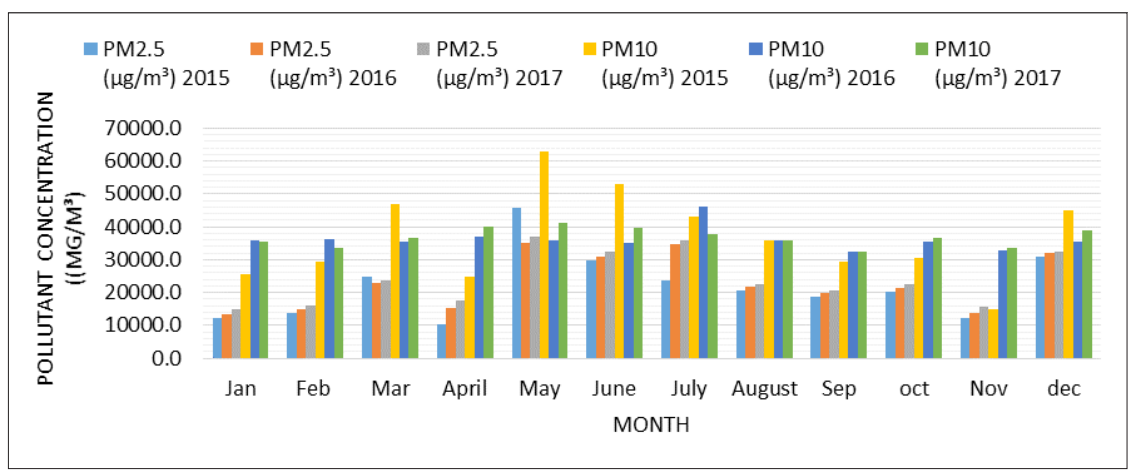

Fig. 5.

Particulate Matter (PM2.5 and PM 10) Concentrations between 2015 and 2017

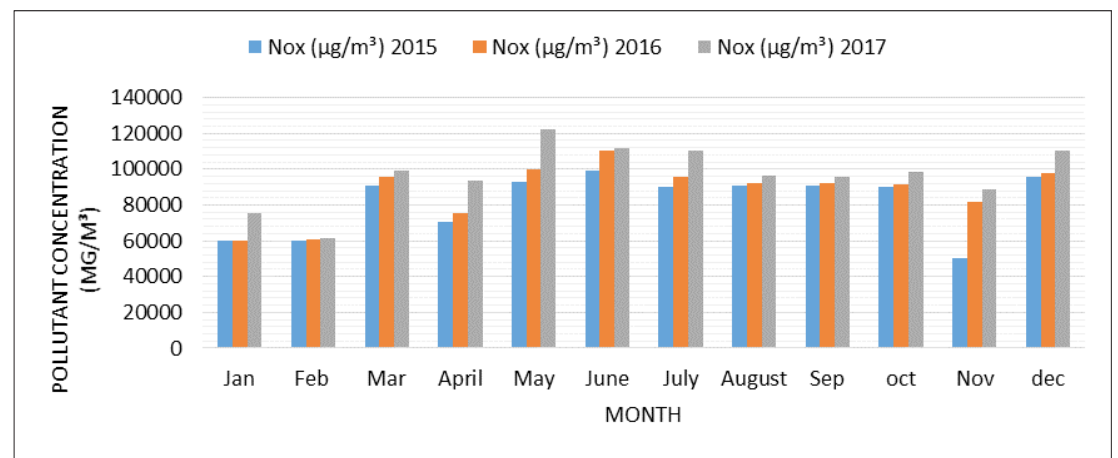

Fig. 6.

Nitrogen Oxides $\left(\mathrm{NO}_{x}\right)$ Concentrations between 2015 and 2017

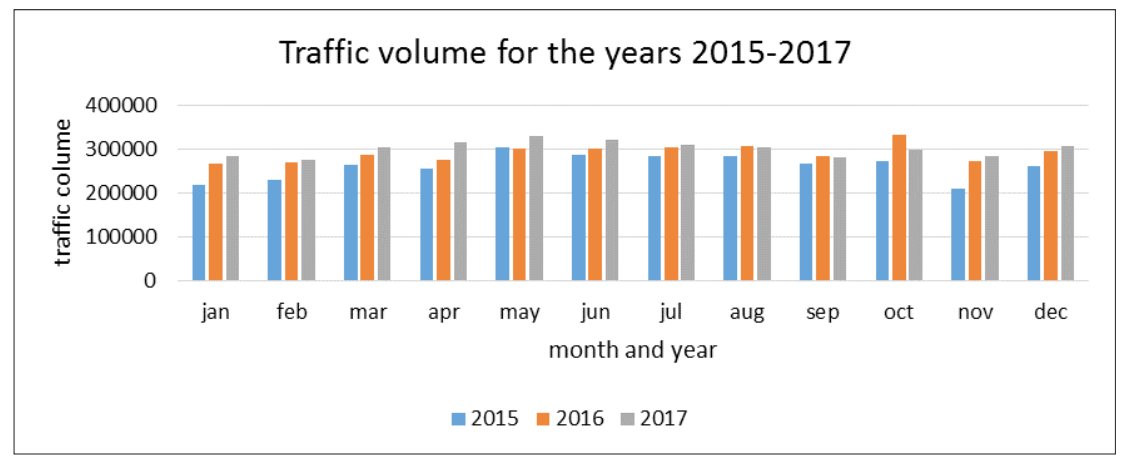

Fig. 7 .

Traffic Volume for the Years 2015-2017 


\section{Data Analysis}

The traffic volume data and air pollutant concentrations were analyzed using moving averages method of Time Series analysis. With the help of time series analysis, the values of traffic volume and different air pollutant concentrations for the years 2020 and 2025 are predicted. The relative percentage increase of traffic volume and pollutant concentrations between the years 2015-2016, 2016-2017, 2017-2020, 2020-2025 were computed. The relationship of AADT and AAPC between the years 2015-2017 has been analyzed to study the impact of increase in traffic volume on different pollutant categories.

The relative percentage increase of the traffic volume and pollutant concentrations are presented in Table 1.

Table 1

Percentage Increase of Traffic Volume and Pollutant Concentrations

\begin{tabular}{|l|l|l|l|l|l|}
\hline S.NO & DESCRIPTION & $\mathbf{2 0 1 5 - 2 0 1 6}$ & $\mathbf{2 0 1 6 - 2 0 1 7}$ & $\mathbf{2 0 1 7 - 2 0 2 0}$ & $\mathbf{2 0 2 0 - 2 0 2 5}$ \\
\hline 1 & Traffic Volume & 11.4 & 13.5 & 24.5 & 35.6 \\
\hline 2 & Carbon Monoxide $(\mathrm{CO})$ & 26.7 & 41.4 & 57.1 & 66.4 \\
\hline 3 & Ozone $\left(\mathrm{O}_{3}\right)$ & 27.2 & 86.9 & 92.5 & 122.1 \\
\hline 4 & Ammonia $\left(\mathrm{NH}_{3}\right)$ & 13.3 & 67.9 & 78.8 & 97.0 \\
\hline 5 & Sulphur Dioxide $\left(\mathrm{SO}_{2}\right)$ & 10.8 & 24.4 & 43.9 & 51.3 \\
\hline 6 & Particulate Matter $\left(\mathrm{PM}_{2.5}\right)$ & 27.5 & 35.1 & 68.8 & 73.4 \\
\hline 7 & Particulate Matter $\left(\mathrm{PM}_{10}\right)$ & 16.9 & 59.3 & 62.2 & 72.7 \\
\hline 8 & Benzene & 12.6 & 29.0 & 46.7 & 50.4 \\
\hline 9 & Nitrogen Oxides $\left(\mathrm{NO}_{x}\right)$ & 24.7 & 31.7 & 42.8 & 56.7 \\
\hline
\end{tabular}

The observations in Table 1 clearly depicts that the percentage increase of traffic volume and pollutant concentrations is directly proportional to each other. There is a hazardous increase in the percentage of pollutant concentrations by the year 2025, clearly indicating the deterioration of the air quality status in the study area.

\subsection{Effect of Traffic Volume on Pollution Concentration}

Further, effect of traffic volume on pollution concentration has been analyzed to observe the extent of increase in each pollutant density with respect to volume. Traffic volume data obtained from field was analyzed to estimate Passenger Car Unit (PCU). Traffic volume was converted into PCU as per the procedure given in IRC 106:1990. The converted volume was plotted with category of each pollutant and the relationship is expressed in the form of scatter plots. The relationship between the variables traffic volume and each category of pollutant are shown in Figures 8(a) to 8(h).

The scatter plots are drawn between Annual Average Daily traffic (AADT) between the years 2015-2017 on X-axis and Annual average daily concentrations of each pollutant category on Y-axis between the years 20152017 to express the relationship and analyze the trend between these variables. 


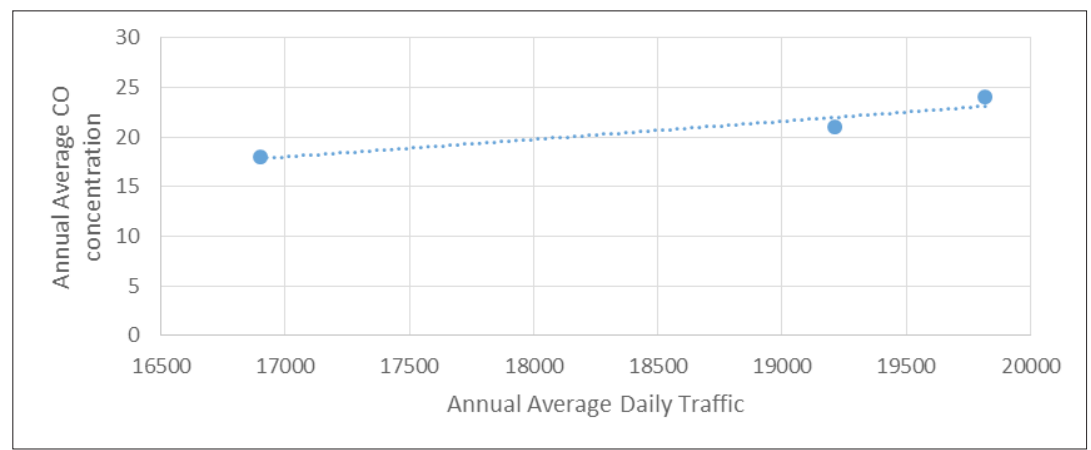

Fig. 8(a).

Plot between AADT and Annual Average CO Concentrations in the Years 2015-2017

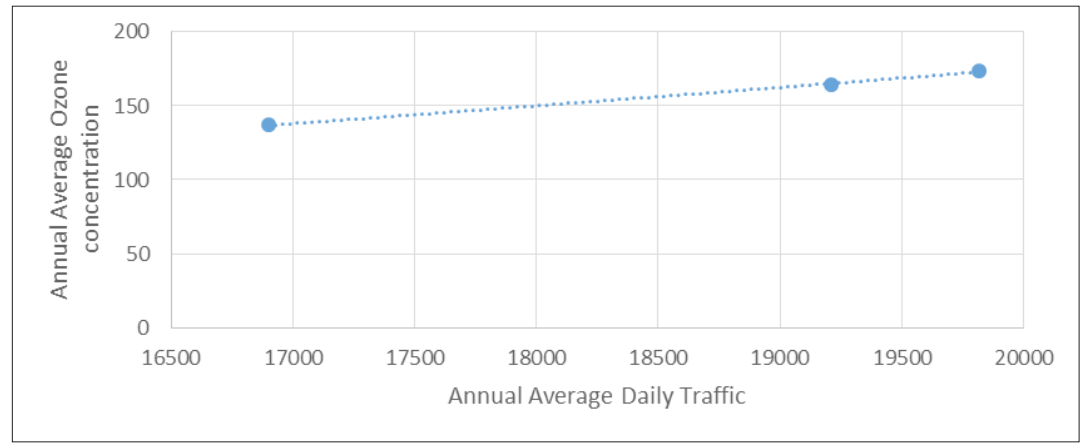

Fig. 8(b).

Plot between AADT and Annual Average Ozone Concentrations in the Years 2015-2017

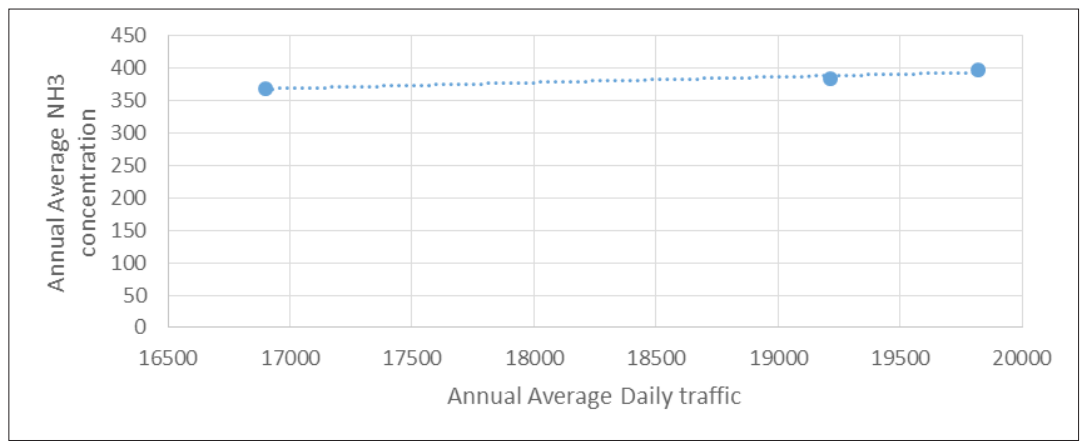

Fig. 8(c).

Plot between AADT and Annual Average $\mathrm{NH}_{3}$ Concentrations in the Years 2015-2017 


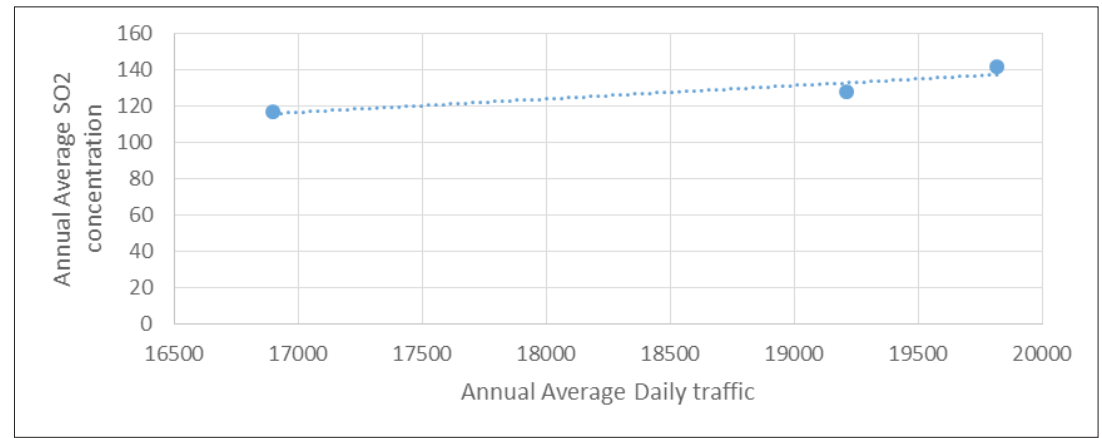

Fig. 8(d).

Plot between AADT and Annual Average $\mathrm{SO}_{2}$ Concentrations in the Years 2015-2017

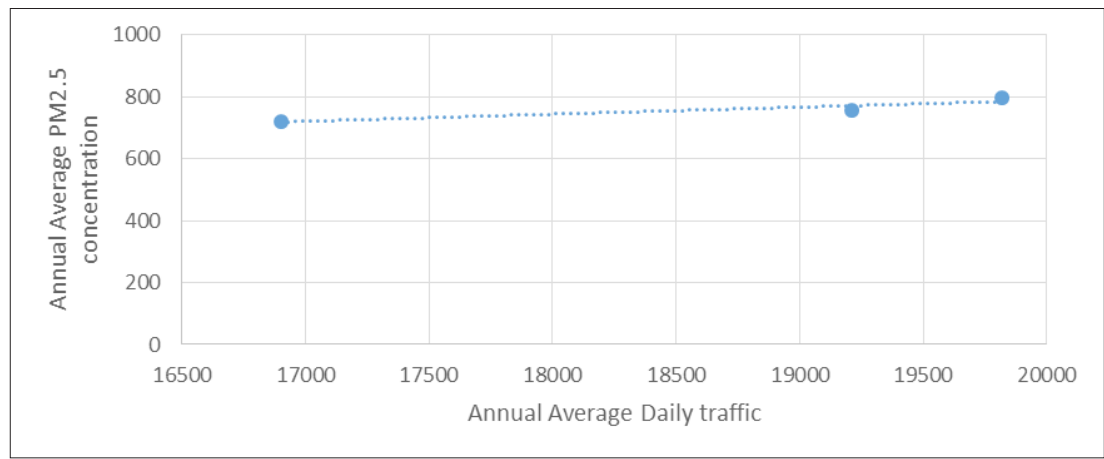

Fig. 8(e).

Plot between AADT and Annual Average PM ${ }_{2.5}$ Concentrations in the Years 2015-2017

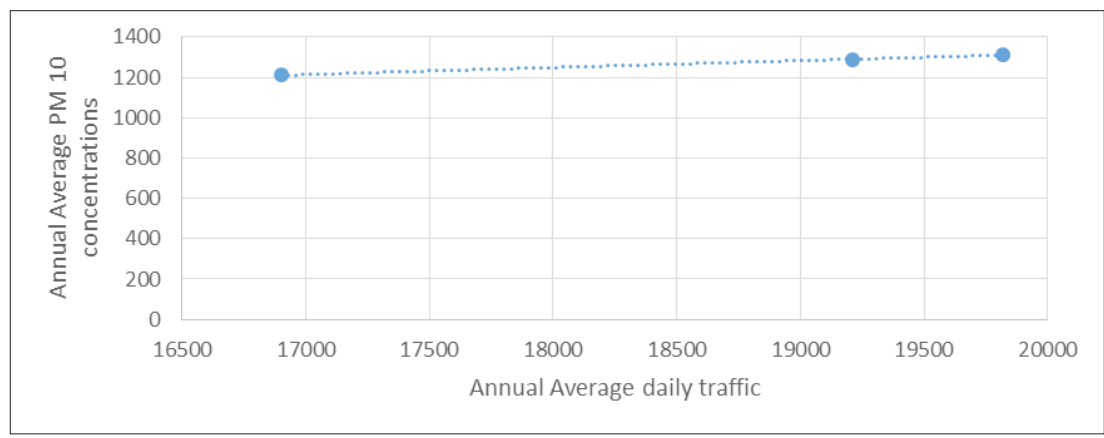

Fig. 8(f).

Plot between AADT and Annual Average PM ${ }_{10}$ Concentrations in the Years 2015-2017 


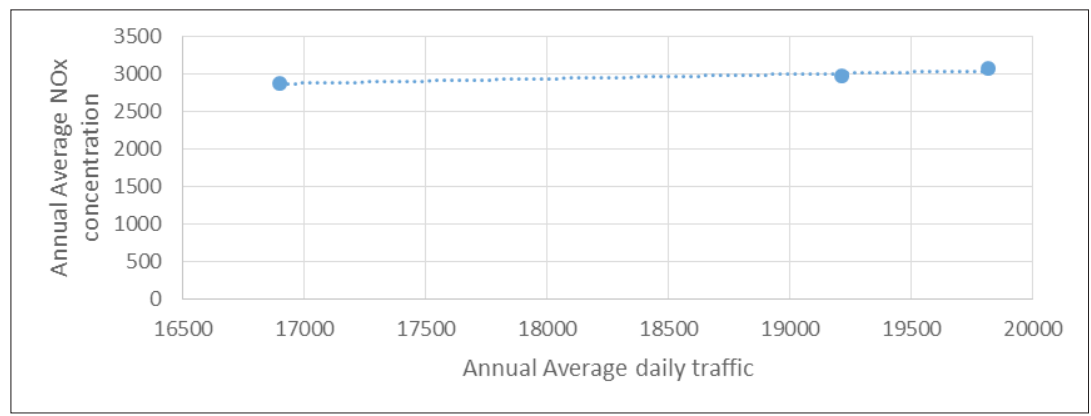

Fig. 8(g).

Plot between AADT and Annual Average $\mathrm{NO}_{X}$ Concentrations in the Years 2015-2017

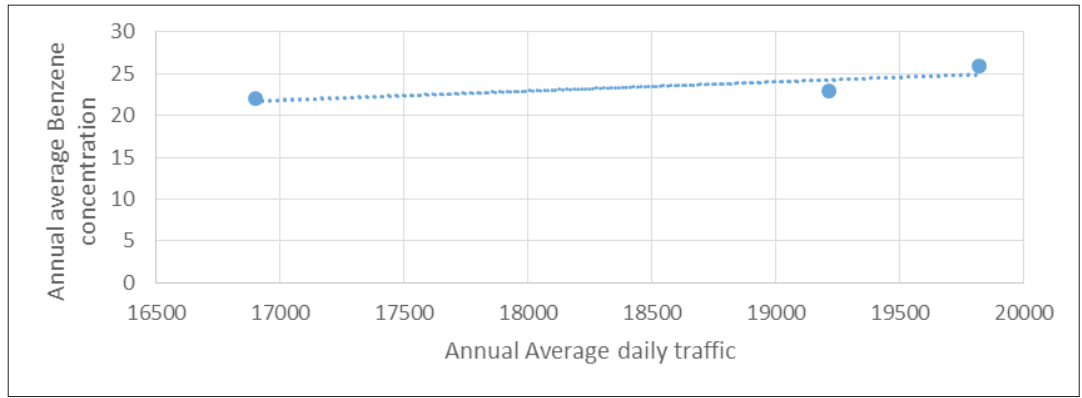

Fig. 8(h).

Plot between AADT and Annual Average Benzene Concentrations in the Years 2015-2017

The relation between AADT and AAPC for each pollutant has been plotted in Fig $8(\mathrm{a})$ to Fig. 8(h). The relationship between AADT and AAPC for each pollutant is positively linear, clearly indicating that, if there is increase in traffic volume, the concentration of each pollutant is linearly increasing. The increase in traffic volume has a significant impact on different pollutant concentrations. At this point, there is a need to regulate the traffic volume on roads to improve the status of air quality in the study area.

\section{Conclusions}

The study revealed that the status of air quality is declining over the years in Tirumala town. It is observed that as the AADT is increasing year by year, the annual average air pollution has also been increased. The traffic volume in the study area is expected to increase by $35.6 \%$ by the year 2025. This causes a huge increase in the concentration of different pollutants by the year 2025. The major pollutant released from vehicles i.e., $\mathrm{CO}$ is expected to increase abnormally by $66.4 \%$ in the future years which is very dangerous to the environment. The Ozone is likely to be increased by $122 \%$ which would be a serious reason for the depletion of ozone layer. The other pollutants such as $\mathrm{NH}_{3}, \mathrm{SO}_{2}, \mathrm{PM}_{2.5}, \mathrm{PM}_{10}$, benzene, $\mathrm{NO}_{\mathrm{x}}$ are also likely to be increase more $50 \%$ of the current status in the forth-coming years clearly anticipating the degradation of air quality in the study area. 
The study on impact of traffic volume on different pollutant concentrations explains that there is a positively increasing linear relationship between the variable AADT and AAPC over the years. The study also explains that increase in traffic volume is the major reason for the increase in air pollution in the study area. The present study will form the basis for taking up good pollution control measures in Tirumala hill not only to protect the environment but also to save its aesthetic values. This study may be further carried out in various towns and cities of India to assess the condition of air quality. It may also be avail to Pollution control Board (PCB) authorities to implement necessary actions to reduce further pollution levels in area. A significant percentage increase in the traffic volume and pollutant concentrations is observed for the year 2025 which would be more hazardous to the environment.

\section{Recommendations}

The following measures can be taken to mitigate the further deterioration of the air quality for the future generations:

- Usage of electrical vehicles instead of petrol or diesel vehicles;

- Continuous monitoring of emission norms for all vehicles going to Tirumala from Tirupathi;

- Implementation of catalytic converters to two, three wheeler vehicles to reduce the smog/pollution from tail pipe of vehicles;

- Plantation of more number of trees and maintaining the greenery to absorb the smoke coming from vehicles;

- Usage of CNG buses or public transport vehicles or shuttle services for people instead of using personalized vehicles;

- Ban on outdated service vehicles should be strictly followed.

\section{Acknowledgement}

I sincerely thank the Pollution Control Board (PCB) Authorities, Tirupathi for providing necessary data.

\section{References}

Alier, M.; Tauler, R. 2013. Multivariate curve resolution of incomplete data multisets, Chemometrics and Intelligent Laboratory Systems 127: 17-28.

Bhardwaj, R.; Pruthi, D. 2016. Time series and predictability analysis of air pollutants in Delhi. In Proceedings of the $2^{\text {nd }}$ International Conference on Next Generation Computing Technologies (NGCT), 553-560.

Boubel, R.W.; Vallero, D.; Fox, D.L.;Turner, B.; Stern, A.C. 2013. Fundamentals of air pollution. Elsevier. 996 p.

Catalano, M.; Galatioto, F.; Bell, M.; Namdeo, A.; Bergantino, A.S. 2016. Improving the prediction of air pollution peak episodes generated by urban transport networks, Environmental science \& policy 60: 69-83.

Davies, H.W.; Vlaanderen, J.J.; Henderson, S.B.; Brauer, M. 2009. Correlation between co-exposures to noise and air pollution from traffic sources, Occupational and environmental medicine 66(5): 347-350.

Dominici, F. 2004. Time-series analysis of air pollution and mortality: a statistical review, Research report (Health Effects Institute) 123: 3-27.

Gouveia, N.; Fletcher, T. 2000. Time series analysis of air pollution and mortality: effects by cause, age and socioeconomic status, Journal of Epidemiology \& Community Health 54(10): 750-755.

Harrison, R.M.; Tilling, R.; Romero, M.S.C.; Harrad, S.; Jarvis, K. 2003. A study of trace metals and polycyclic aromatic hydrocarbons in the roadside environment, Atmospheric Environment 37(17): 2391-2402. 
Khare, M.; Sharma, P. 1999. Performance evaluation of general finite line source model for Delhi traffic conditions, Transportation Research Part D: Transport and Environment 4(1): 65-70.

Kwak, K.H.; Woo, S.; Kim, K.; Lee, S.B.; Bae, G.N.; Ma, Y.I.; Sunwoo, Y.; Baik, J.J. 2018. On-road air quality associated with traffic composition and street-canyon ventilation: Mobile monitoring and CFD modeling, Atmosphere 9(3): 92.

Nagpure, A.S.; Gurjar, B.R. 2012. Development and evaluation of vehicular air pollution inventory model, Atmospheric environment 59: 160-169.

Nagpure, A.S.; Gurjar, B.R.; Kumar, V.; Kumar, P. 2016. Estimation of exhaust and non-exhaust gaseous, particulate matter and air toxics emissions from on-road vehicles in Delhi, Atmospheric environment 127: 118-124.

Pirjola, L.; Paasonen, P.; Pfeiffer, D.; Hussein, T.; Hämeri, K.; Koskentalo, T.; Virtanen, A.; Rönkkö, T.; Keskinen, J.; Pakkanen, T.A.; Hillamo, R.E. 2006. Dispersion of particles and trace gases nearby a city highway: mobile laboratory measurements in Finland, Atmospheric environment 40(5): 867-879.

Reponen, T.; Grinshpun, S.A.; Trakumas, S.; Martuzevicius, D.; Wang, Z.M.; LeMasters, G.; Lockey, J.E.; Biswas, P. 2003. Concentration gradient patterns of aerosol particles near interstate highways in the Greater Cincinnati airshed, Journal of environmental monitoring 5(4): 557-562.
Tchepel, O.; Borrego, C. 2010. Frequency analysis of air quality time series for traffic related pollutants, Journal of Environmental Monitoring 12(2): 544-550.

Wang, H.; Chen, C.; Huang, C.; Fu, L. 2008. On-road vehicle emission inventory and its uncertainty analysis for Shanghai, China, Science of the Total Environment 398(13): 60-67.

Wilson, I.L.N.A.H.; Henshaw, T. 2016. Assessment of Standard Pollutants in A Gas Flaring Region: A Case of Ogba/Egbema/Ndoni Local Government Area In Rivers State of Nigeria, International Journal of Civil Engineering and Technology 7(3): 7-17.

Xue, J.P.; Tian, W.; Zhang, Q.Y. 2010. Development of NOx emission inventory from motor vehicles in Hangzhou and study on its influence on air quality, Research of Environmental Sciences 23(5): 613-618.

Yang, F.; Yu, L.; Song, G.; Wang, L. 2004. Application of small sampling approach to estimating vehicle mileage accumulations for Beijing, Transportation research record 1880(1): 77-82.

Zhou, R.; Wang, S.; Shi, C.; Wang, W.; Zhao, H.; Liu, R.; Chen, L.; Zhou, B. 2014. Study on the traffic air pollution inside and outside a road tunnel in Shanghai, China, PloS one 9(11): 112195.

\section{jitte 407}

